\title{
CORRECTION
}

\section{JUPITER strikes earth}

Valentin Fuster and Sameer Bansilal

Original article Fuster, V. \& Bansilal, S. JUPITER strikes earth. Nat. Clin. Pract. Cardiovasc. Med. 6, 159 (2009).

The third sentence in paragraph 3 should have read "Furthermore, although the study demonstrated high relative-risk reductions, the overall incidence of the composite primary end point was only $2.8 \%$ in the placebo arm, with an absolute risk reduction of 1.2\% (number needed to treat $=83$ ), and the incidence of hard cardiovascular end points was only $1.8 \%$, with an absolute risk reduction of $0.9 \%$ (number needed to treat $=120$ )" rather than number needed to harm, as was indicated.

doi:10.1038/nrcardio.2009.54 